Thomas Ridley-Siegert

is research manager at the Direct Marketing Association (UK). He is responsible for developing and managing the various strands of research the DMA produces. The DMA has a network of more than 1,000 UK company members who are privy to research, free legal advice, political lobbying and industry guidance. Its members connect at regular events that inspire creativity, innovation, responsible marketing and more.

Keywords: permission marketing, customer acquisition, consumer insight

\section{Consumer and marketer responses}

\section{Email preferred by both}

\footnotetext{
Thomas Ridley-Siegert, Direct Marketing Association, DMA House, 70 Margaret Street, London, W1W 8SS, UK

Tel: +44 (0)20 72913300 Fax: +44 (0)20 72913301

E-mail: thomas.ridley-siegert@dma. org.uk
}

\section{Business Intelligence}

\section{Customer acquisition barometer 2015}

\author{
Thomas Ridley-Siegert \\ Received (in revised form): 8th October 2015
}

\begin{abstract}
The DMA has researched consumer attitudes towards permission marketing and data collection in both 2015 and 2014. It has also surveyed marketers about the way they collect personal information, deploy it in their marketing and follow the correct data protection processes. This article reports on the findings from the most recent research and contrasts them with the previous year to highlight trends in behaviour and attitudes.
\end{abstract}

Journal of Direct, Data and Digital Marketing Practice (2015) 17, 93-100. doi:10.1057/dddmp.2015.49

\section{Overview}

The Customer Acquisition Barometer 2015 is the second time the Direct Marketing Association, supported by the Media Octopus, has examined consumer attitudes towards their interactions with marketers, the channels they prefer to be contacted in, how they view providing their personal information and what attitudes they have towards the way that data is subsequently used. Marketers were also surveyed to understand the channel mix they use, attitudes towards permission marketing, and internal controls over data management and usage. Consumer research was carried out by Beautiful Insights among 1,072 consumers, with the DMA conducting research among 164 marketers. A focus group of marketers was also interviewed to explore more deeply the issues identified in the research. Results were compared against similar research carried out in 2014 to identify key trends over the last 12 months.

Consumers and marketers agree strongly on one thing - email is their preferred contact channel. Among consumers, 74 per cent want email from brands they know and 60 per cent want unknown brands to use email. Email is also the most trusted channel among consumers for data sharing (58 per cent). Among marketers, 84 per cent say they are using email (although only 36 per cent say it is their most effective channel).

Nearly twice as many consumers now believe data security is not compromised when data is shared compared with 2014 (20 per cent versus 11 per cent). While 35 per cent believe security does suffer, this is down from 48 per cent in 2014. All channels have benefited from increased confidence that data will be kept secure. The nature of the contact that 


\section{Channels more trusted for data sharing}

\section{Marketers using fewer channels}

\section{Sharing personal information}

\section{Email and websites}

consumers receive once they have provided their personal information might influence their expectations. A concern for marketers should be that only 12 per cent describe their experience as problem-free.

Marketers are using fewer channels in their marketing in 2015 than in 2014. While activity is still spread across social and mobile as well as digital, there is a tighter focus on channels considered to be the most effective, especially email. Across the board, fewer marketers are running the same standard of data collection processes compared with $2014-56$ per cent offer an opt-out at every stage, down from 93 per cent, for example, with only 48 per cent of B2B marketers offering this.

\section{Consumer findings}

When purchasing or making an enquiry in the last 12 months, 60 per cent of consumers claim not to have shared their information, up from 48 per cent in 2014. This is surprising given the inherent need to exchange data during transactions. But this claim may reflect a gap between attitude and action. When asked about specific channels through which they might have shared their data while buying or responding, however, only 26 per cent said they had not shared information. There is also a difference between warm and cold contact when it comes to data sharing - if the consumer has bought from a brand before, 31 per cent claim not to have provided information, but with unknown companies, this rises to 51 per cent - still below the generic level. While the majority of consumers may believe they do not share data, their behaviour says otherwise.

All marketing channels show an increase in the number of consumers sharing data since 2014. Providing data by email is now the major (and still growing) channel, closely followed by a brand's website and price comparison sites (see Figure 1). Social media has more than doubled its data sharing rate to 19 per cent, making it the fifth most likely channel in which consumers will share information. There was also a big rise for in-store data sharing (although there was no growth in face-to-face). Mobile also enjoyed a near-doubling in the number of consumers who had

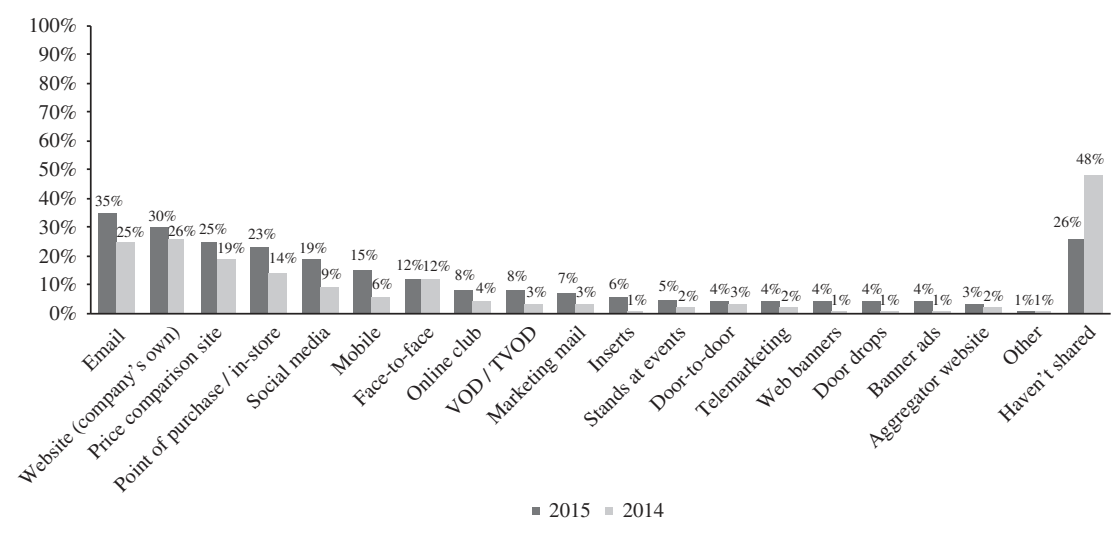

Figure 1: Channels in which data has been shared 2015 versus 2014 


\section{Contact channel preferences}

\section{Apps and social media}

\section{Data security and channel choice}

given out their data - this could reflect new data sharing scenarios, such as downloading apps or connecting to free Wi-Fi.

Email remains the dominant contact channel for known brands at 74 per cent (down slightly from 77 per cent previously) and 60 per cent for unknown brands (see Figure 2). Accessible from mobile, tablet and desktop, it is omnipresent for consumers. Mobile is gaining in preference among consumers as a contact channel. If they have previously bought from or been interested in a company, 15 per cent name SMS and 14 per cent mobile phone as their preferred channel, double or more than double the number in 2014, which saw 7 per cent mention mobile and 6 per cent SMS. But unknown brands have half this preference rate, at 9 per cent for mobile and 7 per cent for SMS.

Apps run a close third for mobile contact at 12 per cent for known brands, although only 4 per cent of consumers mention these for cold contact. Interaction with an app is a positive action by the individual, rather than a passive receipt of a message, which may account for this significant level of acceptance but only for known brands. Social media has increased its preference rate threefold, with 13 per cent choosing it for known brand contact, up from 4 per cent last year. Even cold contact via social media is preferred by 8 per cent of consumers.

Data security is no longer a simple yes/no issue for consumers and is conditional on a number of factors. Channel choice is an important one of those and every route to market has seen improved levels of confidence that information shared through them will be secure. Email is the most trusted to keep data secure, named by 58 per cent in 2015 compared with 43 per cent previously, while a brand's own website scores 54 per cent for
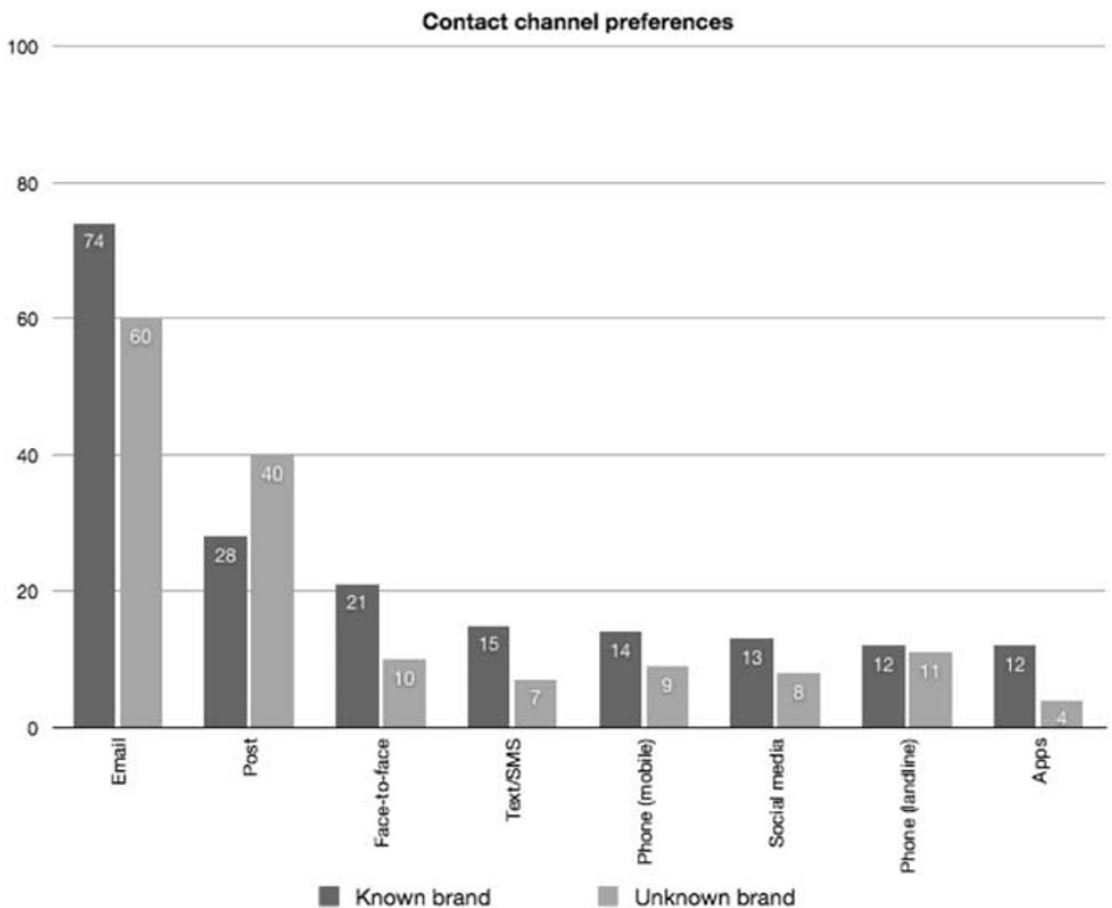

Figure 2: Channels preferred for contact by known/unknown brands 


\section{Growing distrust around data security}

\section{Experiences of data sharing}

\section{Marketing mix getting narrower}

confidence in security, up from 42 per cent (see Figure 3). Social, mobile and other digital channels have also enjoyed a doubling or trebling of their rating for keeping personal information safe. A likely driver of this confidence is the depth of experience and maturity of usage of mobile devices, combined with more visible efforts by brands to demonstrate how secure their sites and channels really are.

Despite this, distrust around data security has also grown for all channels, with social (59 per cent) facing the biggest crisis of confidence. Concerns about data used in advertising mail also saw a surprising increase, up to 38 per cent from 25 per cent, perhaps because personal information (or name and address at least) is openly visible in this channel.

Having provided their data, consumers then experience how it is used by marketers. For only 12 per cent, this presents no problems (see Figure 4). For the rest, there is a list of reasons why they may have become frustrated (and therefore developed different expectations about the controls they should be offered during the value exchange). Top of that list are calls from contact centres based overseas ( 27 per cent), although this has fallen since last year, closely followed by contacts being too frequent (25 per cent). Lack of relevance is a concern for one-fifth, while one in ten say there was a lack of openness about the reasons for the contact.

Arguments can be made about why contacts happen in these ways - but for 6 per cent, their problem is down to having a bad experience.

\section{Marketers findings}

The marketing mix is changing, with the range of channels being used to acquire new customers narrowing and becoming more homogenous.

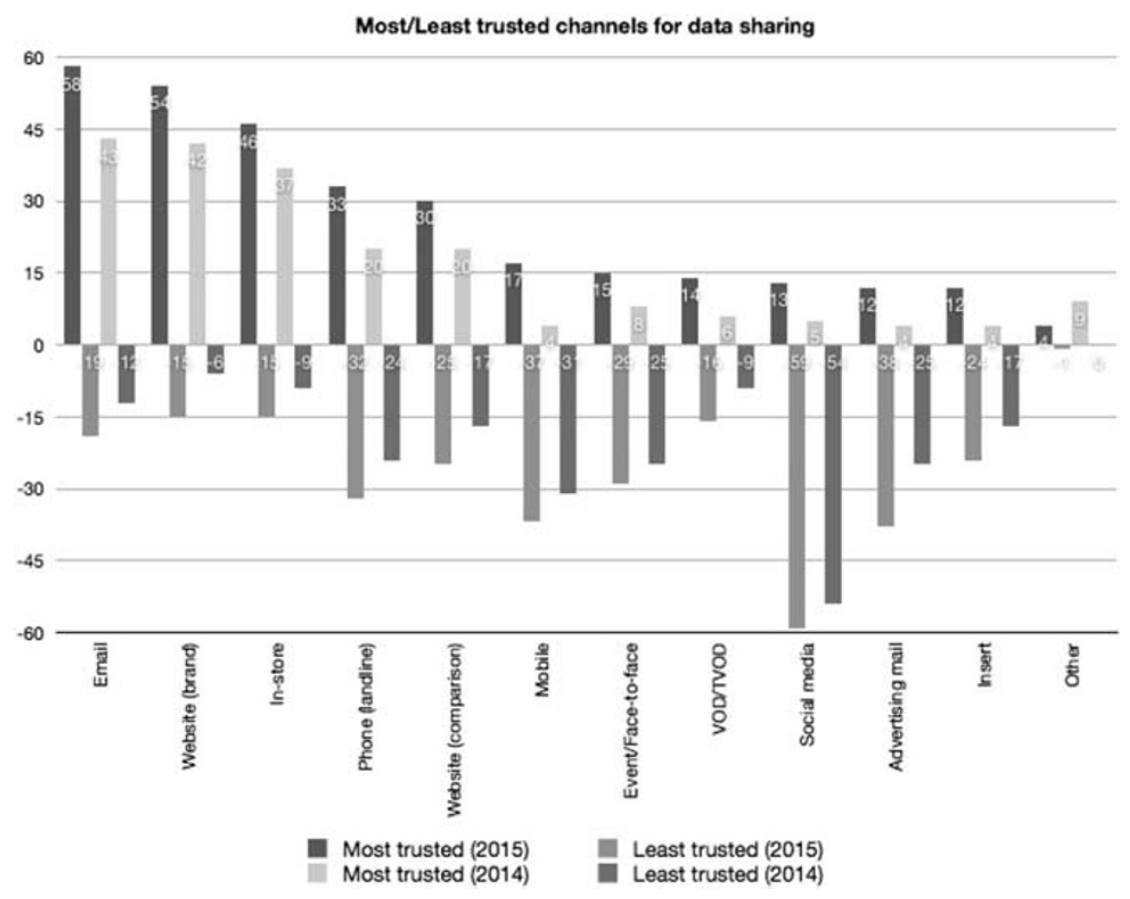

Figure 3: Channels most/least trusted for data sharing 


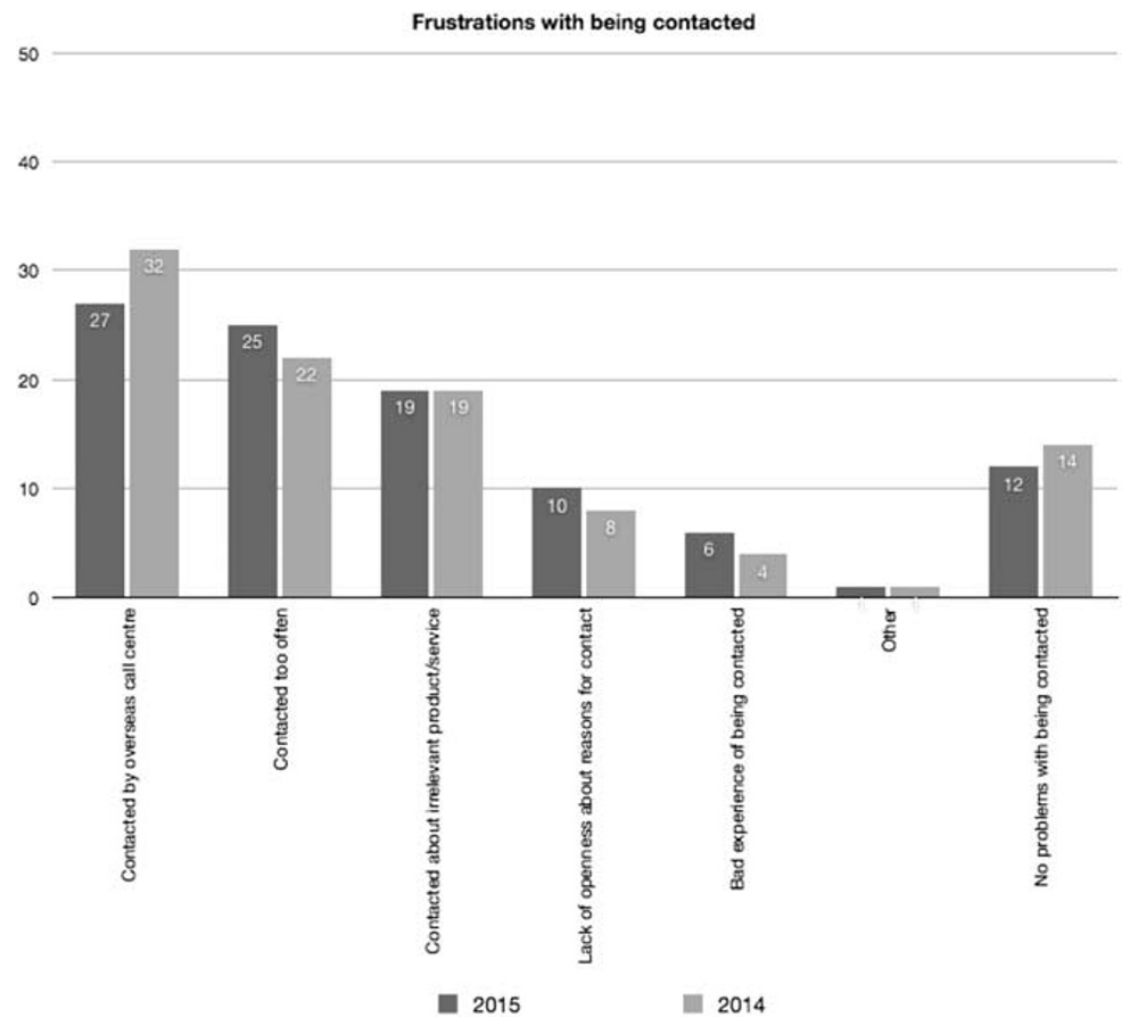

Figure 4: Consumers' frustrations with marketing contact

\section{B2B using fewer channels than B2C}

\section{Most effective acquisition channels}

Across the board, fewer marketers in 2015 mentioned each channel than in 2014 (see Figure 5). Even the most recent areas of focus - social and mobile - have both seen significant drops in use. (It should be noted that last year social media was included as a single option, chosen by 79 per cent, while this year it was split between paid, used by 46 per cent, and organic, used by 60 per cent.) Use of the company's own web site has fallen in usage by 13 per cent. This leaves email as the primary channel for customer acquisition and the only channel to have seen no change year-on-year.

In B2B marketing, six channels dominate, led by email (79 per cent using), website (73 per cent), face-to-face (65 per cent), organic social media ( 55 per cent), direct mail (46 per cent) and telemarketing ( 41 per cent). All other channels are used by one-third of marketers or fewer. In B2C marketing, email (92 per cent) and website ( 87 per cent) are also the lead customer acquisition channels, but a total of 15 different channels were named by at least one-third of marketers. This concentration into email is in line with consumers' own channel preference, since 74 per cent welcome contact from a known brand and 60 per cent from an unknown brand in this medium.

The channel selection being used by marketers for customer acquisition is broadly in line with what consumers name as their preferred channels of contact. At the same time, it does not reflect the effectiveness of those channels in acquiring new customers (see Figure 6). Marketers naming their own website grew to 39 per cent from 30 per cent last year, but email 


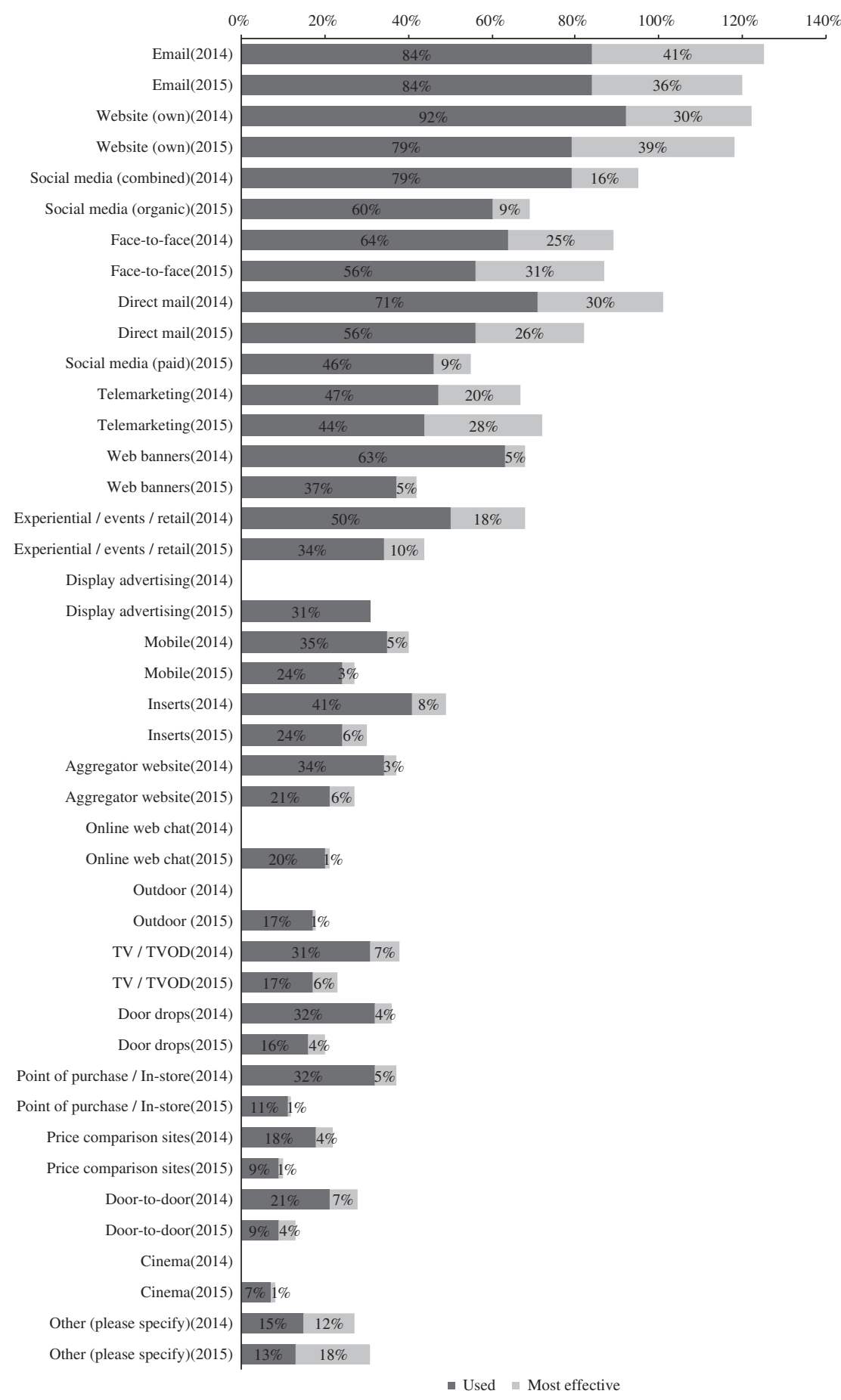

Figure 5: Channels used by marketers for customer acquisition

fell to 36 per cent from 41 per cent despite being the most-used channel. Face-to-face and telemarketing were both chosen more than last year. Both types of social media (organic and paid) gained only mid-ranking scores for effectiveness at 9 per cent, nearly half the level reported last year (although social media was given as a single option in 2014). 
Customer acquisition barometer 2015 迹

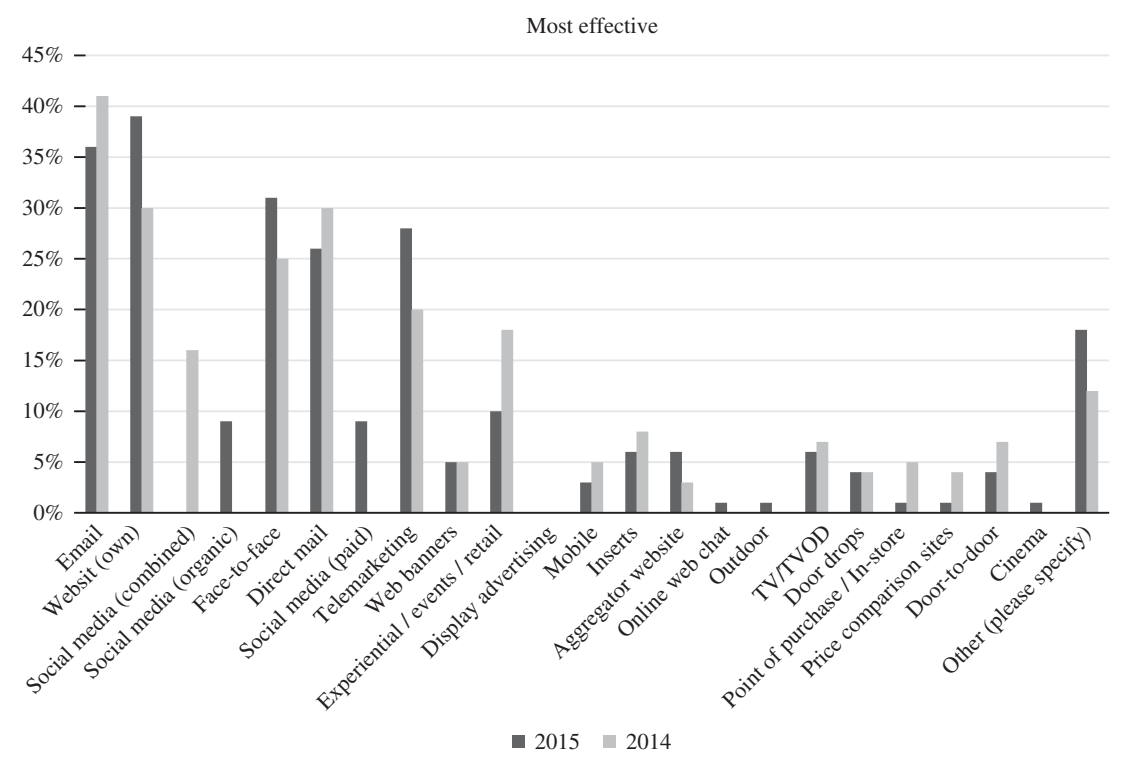

Figure 6: Most effective channels for customer acquisition 2015 versus 2014

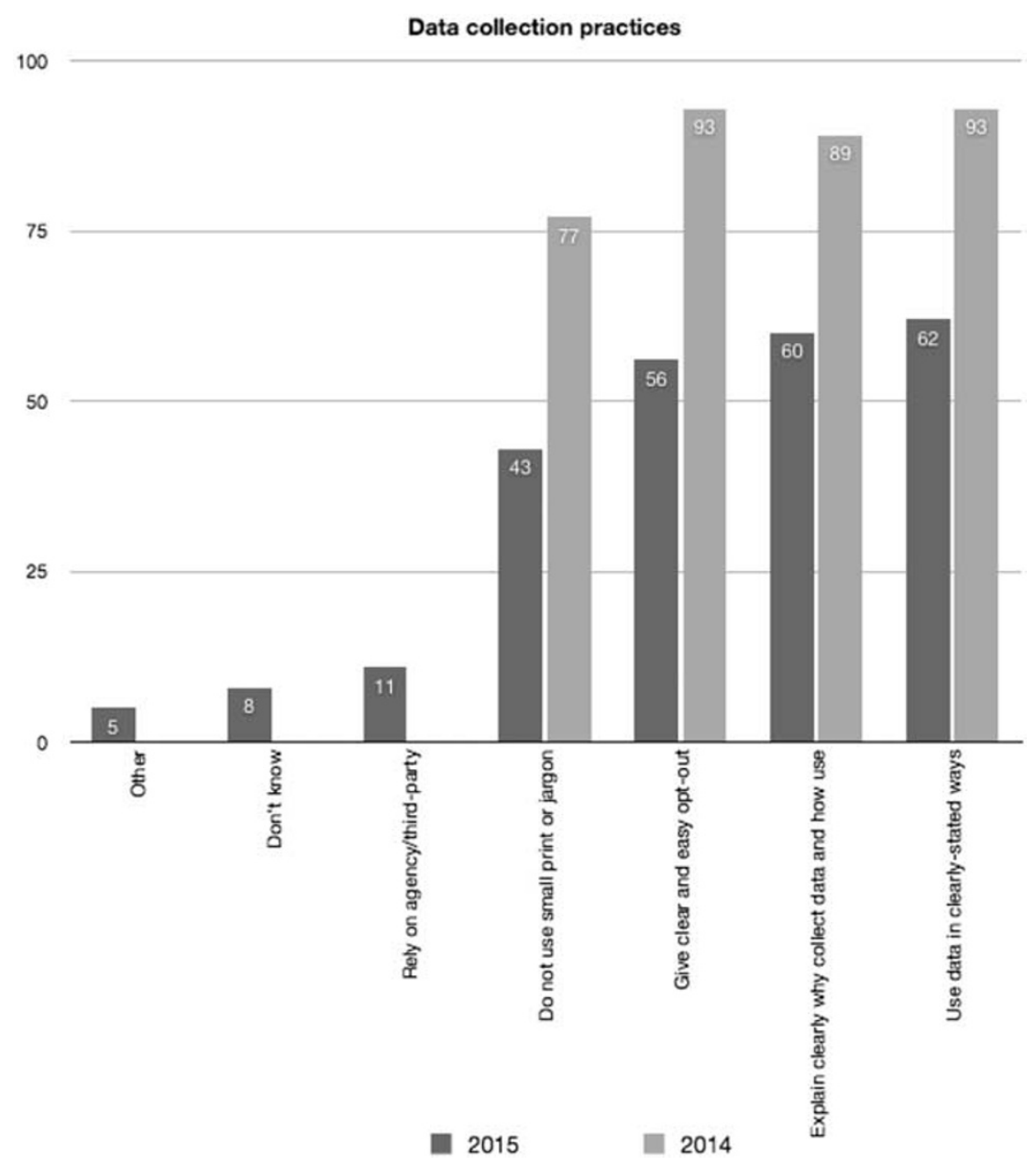

Figure 7: Data collection practices 2015 versus 2014 


\section{Falling levels of compliance}

\section{Less alignment with acquisition}

Organic social media is rated as effective by far more B2B marketers (13 per cent) than B2C marketers (3 per cent), but both sides share a similar view of the performance of paid organic social media ( 8 per cent for B2B compared with 11 per cent for B2C). An important point to note is that social media metrics continue to be less robust than for other channels, making their impact within campaigns harder to assess and compare.

Marketers have legal obligations around data collection, as well as a need to meet consumer expectations about how data is captured and used. Compared with last year, fewer marketers say they are carrying out these processes (see Figure 7). In 2014, nearly all marketers (93 per cent) said they had a data collection policy that offered an opt-out at every stage, but in 2015 this has fallen to just over half ( 56 per cent). It is worth adding that where email addresses or mobile phone numbers are collected for marketing, it is actually an opt-in that is required (unless the individual is already a customer). Clearly stating how data will be used - one of the principles of the Data Protection Act - was upheld by 93 per cent of marketers last year, but now only 62 per cent are being transparent in this way.

Transparency is also less in evidence in data collection notices than before, with 60 per cent of marketers now giving a clear explanation why they need to collect data and how it will be used, compared with 89 per cent last year. Whereas 77 per cent of marketers said they avoided small print or jargon in 2014, only 43 per cent now do so. Customer acquisition marketing and data collection processes now appear to be less aligned. Fewer marketers provide a copy of their privacy policy with all customer communications than a year ago ( 38 per cent versus 50 per cent), whereas 40 per cent now send their policy separately (up from 27 per cent in 2014). 